\title{
Influence of diet enriched with conjugated linoleic acids on their distribution in tissues of rats with DMBA induced tumors
}

\author{
Agnieszka Białek ${ }^{1 *}$, Andrzej Tokarz $^{1 \dagger}$, Agnieszka Dudek $^{1 \dagger}$, Weronika Kazimierska ${ }^{1 \dagger}$, Wojciech Bielecki ${ }^{2 \dagger}$
}

\begin{abstract}
Backround: Conjugated linoleic acids (CLA) are a group of positional and geometric isomers of linoleic acid with proven beneficial influence on health. They show e.g. anticarcinogenic, antiobesity, and antiatherogenic effect. Milk, dairy products and meat of poligastric animals are their most valuable dietary sources, with cis-9, trans-11 CLA (RA rumenic acid) being the predominant isomer. Dietary supplements with CLA became very popular, mainly among the overweight and bodybuilders.

The aim of this study was to examine the influence of the food supplements with conjugated linoleic acid on carcinogenesis in female Sprague-Dawley rats and evaluation of CLA and other fatty acids distribution in their bodies. Animals were divided into four groups depending on the diet supplementation (oil or Bio-C.L.A. (Pharma Nord Denmark) given intragastrically) and presence or absence of carcinogenic agent (7,12-dimethylbenz[a]antharcene). Animals were decapitated at 21st week of experiment and serum and microsomes were extracted.

Results and conclusions: The mammary tumours (adenocarcinoma) occurred in groups treated with DMBA. Diet enriched with CLA decreased the cancer morbidity (67\% in Bio-C.L.A. compared to $88 \%$ in oil) and delayed the cancer induction $(p=0.0018)$. There were no differences in body and organs weight.

The supplement used in the study was a mixture of several fatty acids with the greatest proportion of CLA isomers: trans-10, cis-12 (33\%) and cis-9, trans-11 (31\%). Both of them were present in tissues but the content of rumenic acid was greater. Dietary supplementation had also significant impact on other fatty acids content, both in serum and in microsomes.
\end{abstract}

\section{Background}

Conjugated Linoleic Acid (CLA) is a term for positional and geometrical isomers of octadecadienoic acid with two double bonds separated by only one single bond. They are found in various types of food, mainly in milk and dairy products and meat of ruminants. The predominant CLA isomer in food is cis-9, trans-11-octadecadienoate (Rumenic Acid - RA), which constitutes over $90 \%$ of all CLA isomers [1]. Their content in food differs and depends on many factors such as animal species, season, way of feeding, place of pasture [2-6]. Commercially available supplements are the mixture of two main isomers:

\footnotetext{
* Correspondence: agnieszka.bialek@wum.edu.pl

+ Contributed equally

'Department of Bromatology, Medical University of Warsaw, Banacha 1, 02-097 Warsaw, Poland

Full list of author information is available at the end of the article
}

cis-9, trans-11 CLA and trans-10, cis-12 CLA in equal proportions. This group of fatty acids has been extensively studied for recent years, in both in vivo and in vitro models, because of their beneficial biological effects: protection against cancer [7-10], prevention of atherosclerosis [11-14], reduction of obesity [15-17] and hypertension [18]. However, despite numerous experiments their mechanism of action is still under investigation.

As it is known that many cancers are associated with diet, especially with dietary fat, we have focused on changes in fatty acids profile as a possible effect of CLA supplementation. The objectives of the present study were: to monitor the influence of CLA supplementation on mammary carcinogenesis in rats, to compare the CLA distribution in tissues and to assess their influence on other fatty acids profile.

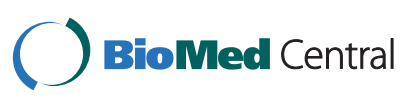

() 2010 Białek et al; licensee BioMed Central Ltd. This is an Open Access article distributed under the terms of the Creative Commons Attribution License (http://creativecommons.org/licenses/by/2.0), which permits unrestricted use, distribution, and reproduction in any medium, provided the original work is properly cited. 


\section{Materials and methods Animals}

This research and guiding principles in the care of laboratory animals were approved by The Local Ethic Commission on Animal Experiments. Female Sprague-Dawley rats $(\mathrm{n}=33)$ were purchased at 30 day of age from Division of Experimental Animals, Department of General and Experimental Pathology (Medical University of Warsaw, Warsaw, Poland). The animal room was kept at $21^{\circ} \mathrm{C}$, in a $12 \mathrm{~h}$ light : $12 \mathrm{~h}$ dark cycle. A standard diet composed of $22.0 \%$ protein, $4.0 \%$ fat, $30.0 \%$ starch, $5.0 \%$ fibre, $6.5 \%$ minerals (Labofeed H, Wytwórnia pasz "Morawski”, Żurawia 19, Kcynia, Poland) was fed ad libitum. The daily food consumption was about $10 \mathrm{~g}$ per rat. After 1-week adaptation animals were randomly divided into four groups of $8-9$ each. All rats from groups A1 and B1 received intragastrically at 50 days of age a single dose of $80 \mathrm{mg} / \mathrm{kg}$ body weight of carcinogenic agent - DMBA (7,12-Dimethylbenz [a] anthracene, approx. 95\%, Sigma-Aldrich) for the induction of mammary tumours. From that day all animals were fed different dietary supplementation (oil - groups A1 and G1, or Bio-C.L.A. (Pharma Nord Denmark) - groups B1 and $\mathrm{D} 1$, given intragastrically $0.15 \mathrm{~cm}^{3} /$ day) for the following 15 weeks. During this period rats were palpated weekly to detect the appearance of tumours. Table 1 shows the characteristic of experimental groups. The fatty acids daily intake is shown in Figure 1. The experiment was terminated at the end of 21 week. All animals were decapitated and exsanguinated.

\section{Histopathological examination}

The effectiveness of cancer induction in DMBA-treated groups (A1 and B1) was determined as the percentage of animals with tumours. Tumours were collected during necropsy and some of them were fixed in $10 \%$ formalin. They were identified as adenocarcinomas and papillary adenocarcinomas of mammary gland. In nonDMBA-treated groups (D1 and G1) there were no spontaneous tumours.

\section{Preparation of serum and microsomes}

Serum was obtained by the centrifugation of blood for $10 \mathrm{~min}$ at $3000 \mathrm{rpm}$ at $4^{\circ} \mathrm{C}$ and stored at $-20^{\circ} \mathrm{C}$ in Eppendorf test tubes until further analysis.
Hepatic microsomes were prepared according to modification of the Kłyszejko-Stefanowicz method [19]. A sample of liver $(4 \mathrm{~g})$ was mechanically homogenized in saccharose solution $\left(16 \mathrm{~cm}^{3} ; 0.25 \mathrm{~mol} / \mathrm{dm} 3\right)$ buffered with TRISS-buffer ( $\mathrm{pH} 7.4)$. Homogenate was centrifuged for $10 \mathrm{~min}$ at $4000 \mathrm{rpm}$ at $4^{\circ} \mathrm{C}$. The sediment was discarded and the supernatant fluid was centrifuged for $20 \mathrm{~min}$ at $16000 \times \mathrm{g}$ at $4^{\circ} \mathrm{C}$. The sediment was discarded and the supernatant was centrifuged for $75 \mathrm{~min}$ at $100000 \times \mathrm{g}$ at $4^{\circ} \mathrm{C}$. The supernatant was discarded and the pellet was resuspended in $4 \mathrm{~cm}^{3} 0.25 \mathrm{~mol} / \mathrm{dm} 3$ saccharose solution. The suspension of hepatic microsomes was stored in Eppendorf test tubes at $-20^{\circ} \mathrm{C}$ until further analysis.

\section{Fatty acids analysis}

Fatty acid analysis was made with GC with capillary column and flame-ionization detection.

The rat serums were thawed only once and samples of $100 \mu \mathrm{l}$ were trans-esterificated according to the procedure of Bondia-Pons et al. with slight modifications [20]. Without prior lipids extraction each sample was hydrolyzed by heating with $2.5 \mathrm{~cm}^{3}$ sodium methylate reagent $\left(0.5 \mathrm{~mol} / \mathrm{dm}^{3}\right)$ at $80^{\circ} \mathrm{C}$ and fatty acids were converted to methyl esters by heating with $2.5 \mathrm{~cm}^{3}$ of $14 \%$ boron trifluoride-methanol reagent at $80^{\circ} \mathrm{C}$ for $3 \mathrm{~min}$. FAME were isolated with hexane $\left(2 \times 0.5 \mathrm{~cm}^{3}\right)$ after adding $1.0 \mathrm{~cm} 3$ of saturated sodium chloride solution. Organic extracts were dried with anhydrous sodium sulphate and evaporated to dryness under a stream of nitrogen. FAME were diluted in $20 \mu \mathrm{l}$ of hexane and stored at $-20^{\circ} \mathrm{C}$. They were separated and quantified by GC using Shimadzu GC-17A chromatograph equipped with flame ionization detector. Injector was heated to $250^{\circ} \mathrm{C}$ and detector was heated to $270^{\circ} \mathrm{C}$. Separation was performed on BPX 70 capillary column $(60 \mathrm{~m} \times 0.25 \mathrm{~mm}$ i.d., film thickness: $0.20 \mu \mathrm{m}, \mathrm{SGE}$ ) with helium as the carrier gas. The initial oven temperature was $140^{\circ} \mathrm{C}$ for $1 \mathrm{~min}$, thereafter increased by $20^{\circ} \mathrm{C} / \mathrm{min}$ to $200^{\circ} \mathrm{C}$ and held for $20 \mathrm{~min}$ and then increased by $5^{\circ} \mathrm{C} / \mathrm{min}$ to $220^{\circ} \mathrm{C}$ and held for $25 \mathrm{~min}$. The whole analysis lasted $53 \mathrm{~min}$. FAME standards (Supelco 37 Component FAME Mix), CLA FAME reference standard (Nu-Chek-Prep) and RA FAME standard (methyl 9 cis 11 trans conjugated

Table 1 Characteristics of experimental groups

\begin{tabular}{|c|c|c|c|c|c|c|c|}
\hline Group & Number & Supplementation & $\begin{array}{l}\text { Carcinogenic } \\
\text { agent }\end{array}$ & Morbidity & $\begin{array}{l}\text { Age of tumour appearance } \\
\text { (day of life) mean } \pm \text { SD }\end{array}$ & $\begin{array}{l}\text { Number of tumours per } \\
\text { individual mean } \pm \text { SD }\end{array}$ & $\begin{array}{l}\text { Tumour weight } \\
\text { (g) mean } \pm \text { SD }\end{array}$ \\
\hline $\mathrm{A} 1$ & 8 & + oil & $+\mathrm{DMBA}$ & $88 \%$ & $106 \pm 14^{*}$ & $1,6 \pm 1,1$ & $3,76 \pm 3,37$ \\
\hline B1 & 9 & + CLA & $+\mathrm{DMBA}$ & $67 \%$ & $143 \pm 19^{*}$ & $0,9 \pm 0,8$ & $2,69 \pm 2,32$ \\
\hline G1 & 8 & + oil & - & - & & & \\
\hline D1 & 8 & + CLA & - & - & & & \\
\hline
\end{tabular}

(* significant differences between groups in Student's $\mathrm{t}$ - test) 


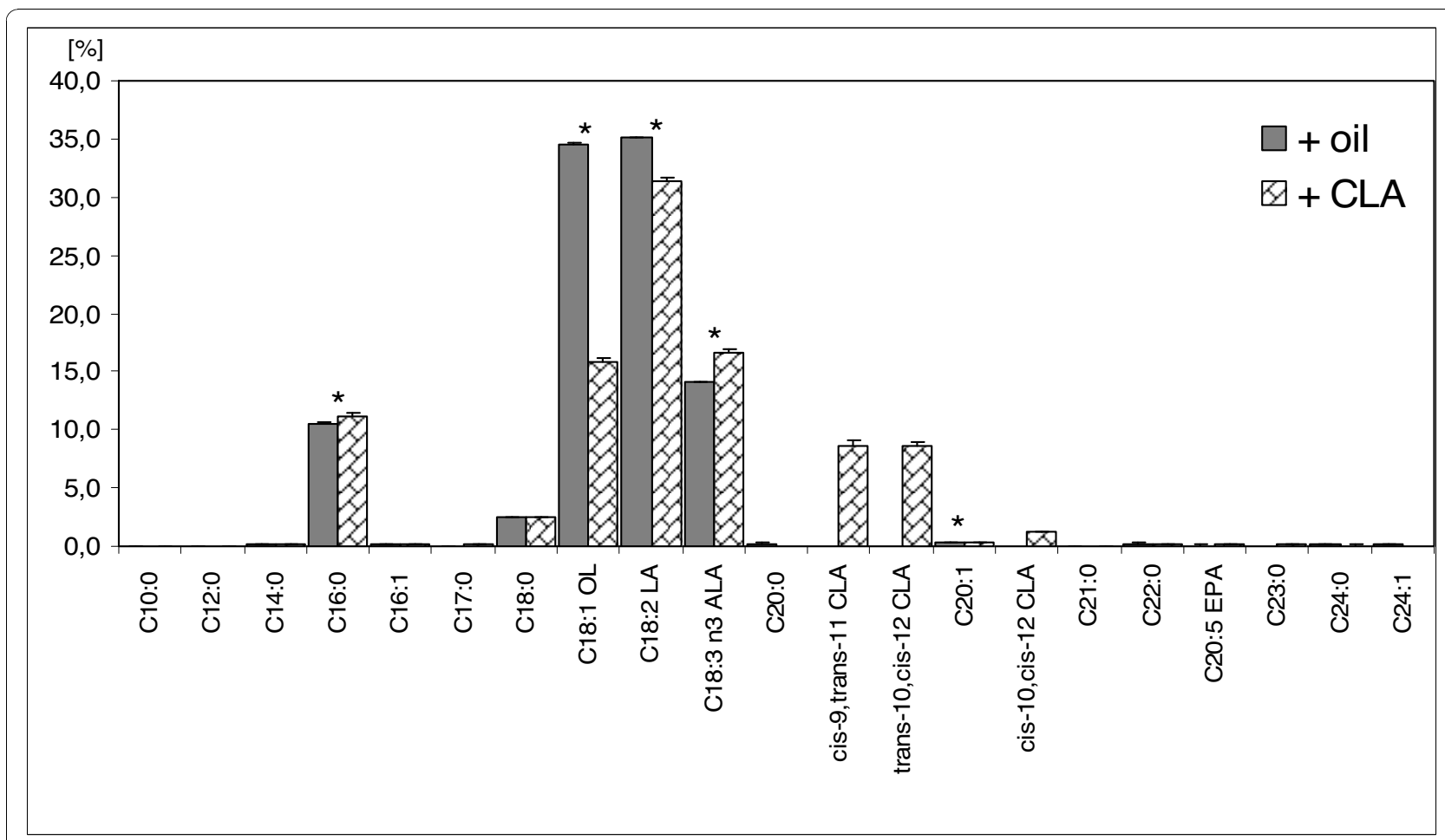

Figure 1 Fatty acids composition of experimental diets (\% of total fatty acids).

linoleate, $\mathrm{Nu}$-Chek-Prep) were used to identify the fatty acids present in samples.

The hepatic microsomes samples were thawed only once and lipids were extracted according to Folch et al. with slight modification [21]. $200 \mu \mathrm{l}$ of microsomal suspensions were mixed with $2.5 \mathrm{~cm}^{3}$ chloroform : methanol $(2: 1, \mathrm{v} / \mathrm{v})$ and after vigorous shaking the chloroform layer was separated. The residue was mixed with $1.5 \mathrm{~cm}^{3}$ chloroform : methanol $(2: 1, \mathrm{v} / \mathrm{v})$ and the extraction was repeated. Combined chloroform layers were centrifuged for $10 \mathrm{~min}$ at $3000 \mathrm{rpm}$ and the sediment was discarded. The organic extract was evaporated to dryness under a stream of nitrogen. The residue was taken for the preparation of FAME according to procedure previously described for serum.

The protein content of hepatic microsomes was measured by the method of Lowry et al. [22].

\section{Statistical analysis}

Results were evaluated with Statistica 9.0 (StatSoft, Poland). The data were tested for normality with Shapiro Wilk test. The Student's t-test and ANOVA were used to test differences between groups for variables following normality and Mann - Whitney U-test and Kruskal Wallis test was performed in case of the shortage of normal distribution. $\mathrm{P}$ - value $\leq 0.05$ was considered significant. All data are mean values \pm standard deviation.

\section{Results and discussion}

The percentage of tumour-bearing animals in each DMBA-treated group is shown in Table 1. The higher effectiveness of cancer induction was observed in A1 group supplemented with oil. 7 of 8 animals in this group developed tumours, and 2 of them had 3 tumours, 2 had 2 tumours and 3 had 1 tumour. CLA supplementation decreased the incidence of tumours (67\% in B1 group in comparison with $88 \%$ in A1 group). 6 of 9 rats supplemented with CLA developed tumours, and 2 animals had 2 tumours each. There were no significant differences in the mean number of tumours per rat in DMBA-treated groups although the percentage of animals with multiple tumours was much higher in group supplemented with oil than in CLA supplemented group (57\% in A1 group in comparison with $33 \%$ in $\mathrm{B} 1$ group). That confirms the greater efficiency of DMBA-induced mammary carcinogenesis in $\mathrm{A} 1$ group and suggests the greater invasiveness of those tumours. There were no significant differences in the mean weight of single tumour between DMBAtreated groups but we observed the tendency to developing heavier tumours in A1 group supplemented with oil. However 2 of 3 single tumours appeared to be much heavier than the rest of tumours in A1 group (10.50 g and $11.93 \mathrm{~g}$ respectively) and the range of tumour weight was wider in A1 group in comparison with B1 group. In B1 group there was only 1 single tumour much heavier than 
the rest of them $(8.51 \mathrm{~g})$. Moreover the first tumour in group A1 appeared on average 5 weeks earlier than in group B1 ( $p=0.0018)$. That indicates the ability of CLA to inhibit the mammary adenocarcinoma development. The lack of significant differences in the tumours weight and in the number of tumours per rat between A1 and B1 groups may be the result of the strength of action of applied carcinogenic agent in the experimental conditions. 7,12-Dimethylbenz[a]anthracene administered intragastrically in a single dose of $80 \mathrm{mg} / \mathrm{kg}$ body weight appeared to be so effective in the induction of mammary tumours in both groups, that the preventive action of Conjugated Linoleic Acid was not efficient enough and confirmed with significant differences in all examined parameters. Observed retardation and the tendency to develop fewer and slighter tumours in CLA supplemented group clearly indicates the protective meaning of this compounds in mammary carcinogenesis.

FAME profiles of serum and microsomes were measured using GC. In our experiment we analysed 21 fatty acids. C20:4 n-6, C18:2 n-6, C16:0, C18:0 and C18:1 n-9 were found to be the main fatty acids in the serum of all investigated groups (Table 2) whereas C18:0, C20:4 n-6, C16:0, C18:2 n-6 and C22:6 n-3 were the most common in the hepatic microsomes (Table 3). Our observations were similar to those of other authors. Bondia-Pons et. al found C18:2 n-6, C16:0, C20:4 n-6,
C18:1 n-9 and C18:0 to be the most prominent in rats' plasma [20]. The slight differences e.g. in share of AA could have been caused by different fatty acids profiles of applied diets. There were significant differences in fatty acid concentration among examined groups. A1 showed the highest concentration of EPA in serum and microsomes, significantly higher than other groups. Also C15:0 amount in microsomes of A1 was considerably greater. In contrast, the $\mathrm{C} 12: 0$ content in serum samples of this group was the lowest. We observed significantly higher concentration of $\mathrm{C} 12: 0$ and $\mathrm{C} 17: 1$, and significantly lower concentration of $\mathrm{C} 18: 3 \mathrm{n}-3$ and $\mathrm{C} 22: 6 \mathrm{n}-3$ in serum of G1. The highest C18:1 n-9 level was observed in the samples of serum obtained from rats in groups A1 and G1, whose diet contained noticeably more of this fatty acid (Figure 1). Similar dependence was evident for the C22:6 n-3 concentration. Jelińska et al. found that higher concentration of C18:3 n-3 in administered diet increased the EPA and DHA levels in liver phospholipids of both non-DMBA- and DMBAtreated rats [23]. Diet of B1 and D1 group, supplemented with Bio-C.L.A., was significantly richer in C18:3 n-3 which caused the increased content of this fatty acid's metabolite - C22:6 n-3 in serum of these groups. DHA concentration in hepatic microsomes was also remarkably higher in CLA-treated groups. This observation is in agreement with that of Eder et al. [24], who measured

Table 2 Fatty acids profile in serum of investigated dietary groups

\begin{tabular}{|c|c|c|c|c|c|}
\hline \multirow[b]{3}{*}{ C12:0 } & A1 & B1 & G1 & D1 & \multirow{3}{*}{$\begin{array}{c}\mathbf{p} \text { value }<\mathbf{0 , 0 5} \\
0,0234\end{array}$} \\
\hline & \multicolumn{4}{|c|}{ Mean \pm SD [\%] } & \\
\hline & $0,03 \pm 0,01$ & $0,04 \pm 0,01$ & $0,05 \pm 0,01$ & $0,04 \pm 0,01$ & \\
\hline C14:0 & $0,25 \pm 0,04$ & $0,24 \pm 0,03$ & $0,25 \pm 0,05$ & $0,25 \pm 0,02$ & \\
\hline C15:0 & $0,36 \pm 0,04$ & $0,35 \pm 0,06$ & $0,27 \pm 0,06$ & $0,32 \pm 0,05$ & 0,0135 \\
\hline C16:0 & $17,87 \pm 1,83$ & $17,75 \pm 1,36$ & $16,21 \pm 1,33$ & $16,50 \pm 1,11$ & \\
\hline C16:1 & $0,96 \pm 0,57$ & $0,52 \pm 0,13$ & $0,56 \pm 0,18$ & $0,50 \pm 0,11$ & \\
\hline C17:0 & $0,51 \pm 0,06$ & $0,51 \pm 0,08$ & $0,53 \pm 0,08$ & $0,55 \pm 0,05$ & \\
\hline C17:1 & $0,07 \pm 0,03$ & $0,06 \pm 0,01$ & $0,09 \pm 0,01$ & $0,08 \pm 0,01$ & 0,0121 \\
\hline C18:0 & $13,71 \pm 1,61$ & $14,38 \pm 1,25$ & $16,98 \pm 0,67$ & $15,98 \pm 1,11$ & 0,0000 \\
\hline C18:1 n-9 & $9,14 \pm 1,38$ & $7,65 \pm 0,64$ & $8,56 \pm 0,89$ & $7,19 \pm 1,01$ & $0,0075^{*}$ \\
\hline C18:2 n-6 & $21,16 \pm 1,25$ & $21,81 \pm 0,72$ & $18,49 \pm 1,29$ & $20,04 \pm 1,03$ & 0,0000 \\
\hline C18:3n-6 & $0,36 \pm 0,07$ & $0,29 \pm 0,05$ & $0,39 \pm 0,05$ & $0,39 \pm 0,06$ & 0,0050 \\
\hline C18:3 n-3 & $2,52 \pm 0,48$ & $2,86 \pm 0,37$ & $2,14 \pm 0,41$ & $2,34 \pm 0,39$ & 0,0085 \\
\hline C20:0 & $0,10 \pm 0,04$ & - & $0,07 \pm 0,01$ & 0,06 & \\
\hline cis-9, trans-11 CLA & $0,05 \pm 0,03$ & $0,40 \pm 0,12$ & - & $0,34 \pm 0,11$ & 0,0037 \\
\hline trans-10, cis-12 CLA & - & $0,16 \pm 0,08$ & - & $0,10 \pm 0,04$ & \\
\hline$C 20: 3 n-6$ & $0,66 \pm 0,28$ & $0,42 \pm 0,06$ & $0,36 \pm 0,05$ & $0,36 \pm 0,05$ & $0,0026^{*}$ \\
\hline C20:4 n-6 & $18,93 \pm 3,88$ & $20,05 \pm 1,03$ & $24,20 \pm 2,01$ & $23,44 \pm 1,85$ & $0,0004^{*}$ \\
\hline$C 20: 3 n-3$ & $0,21 \pm 0,08$ & $0,18 \pm 0,10$ & $0,21 \pm 0,03$ & $0,22 \pm 0,10$ & \\
\hline C20:5 n-3 & $2,70 \pm 0,40$ & $2,08 \pm 0,41$ & $1,65 \pm 0,32$ & $2,01 \pm 0,30$ & 0,0000 \\
\hline C24:0 & $0,09 \pm 0,03$ & $0,09 \pm 0,01$ & $0,07 \pm 0,02$ & $0,06 \pm 0,01$ & 0,0315 \\
\hline$C 22: 6 n-3$ & $4,13 \pm 0,50$ & $4,44 \pm 0,71$ & $3,75 \pm 0,37$ & $4,45 \pm 0,38$ & 0,0315 \\
\hline
\end{tabular}


Table 3 Fatty acids profile in hepatic microsomes of investigated dietary groups

\begin{tabular}{|c|c|c|c|c|c|}
\hline \multirow[b]{3}{*}{ م. } & A1 & B1 & G1 & D1 & \multirow{3}{*}{$\mathrm{p}$ value $<0,05$} \\
\hline & \multicolumn{4}{|c|}{ Mean \pm SD [\%] } & \\
\hline & $0,08 \pm 0,05$ & $0,05 \pm 0,02$ & $0,05 \pm 0,02$ & $0,07 \pm 0,03$ & \\
\hline C14:0 & $0,29 \pm 0,10$ & $0,22 \pm 0,05$ & $0,22 \pm 0,08$ & $0,22 \pm 0,06$ & \\
\hline C15:0 & $0,25 \pm 0,04$ & $0,22 \pm 0,03$ & $0,20 \pm 0,06$ & $0,20 \pm 0,03$ & 0,0065 \\
\hline C16:0 & $18,38 \pm 1,54$ & $18,63 \pm 1,76$ & $16,09 \pm 1,31$ & $16,62 \pm 1,01$ & 0,0019 \\
\hline C16:1 & $0,57 \pm 0,32$ & $0,32 \pm 0,10$ & $0,36 \pm 0,19$ & $0,23 \pm 0,05$ & $0,0140^{*}$ \\
\hline C17:0 & $0,64 \pm 0,09$ & $0,62 \pm 0,09$ & $0,64 \pm 0,10$ & $0,67 \pm 0,06$ & \\
\hline C17:1 & $0,07 \pm 0,02$ & $0,07 \pm 0,01$ & $0,11 \pm 0,02$ & $0,10 \pm 0,02$ & 0,0001 \\
\hline C18:0 & $23,48 \pm 3,13$ & $23,33 \pm 1,72$ & $25,94 \pm 1,95$ & $27,32 \pm 2,01$ & 0,0023 \\
\hline C18:1 n-9 & $8,03 \pm 3,88$ & $5,80 \pm 0,68$ & $6,67 \pm 1,47$ & $4,59 \pm 0,76$ & $0,0009^{*}$ \\
\hline$C 18: 2 n-6$ & $14,37 \pm 1,59$ & $15,47 \pm 1,11$ & $13,84 \pm 1,19$ & $13,56 \pm 1,61$ & 0,0383 \\
\hline$C 18: 3 n-6$ & $0,18 \pm 0,04$ & $0,15 \pm 0,04$ & $0,21 \pm 0,03$ & $0,20 \pm 0,04$ & 0,0061 \\
\hline C18:3n-3 & $1,53 \pm 0,30$ & $1,86 \pm 0,32$ & $1,39 \pm 0,32$ & $1,29 \pm 0,39$ & 0,0068 \\
\hline C20:0 & $0,08 \pm 0,03$ & 0,05 & $0,07 \pm 0,06$ & 0,09 & \\
\hline cis-9, trans-11 CLA & $0,09 \pm 0,06$ & $0,33 \pm 0,09$ & - & $0,25 \pm 0,10$ & 0,0128 \\
\hline trans-10, cis-12 CLA & - & $0,16 \pm 0,08$ & - & $0,08 \pm 0,05$ & \\
\hline$C 20: 3 n-6$ & $0,69 \pm 0,29$ & $0,44 \pm 0,07$ & $0,40 \pm 0,10$ & $0,41 \pm 0,07$ & $0,0022^{*}$ \\
\hline$C 20: 4 n-6$ & $16,67 \pm 2,79$ & $17,28 \pm 0,64$ & $20,31 \pm 1,79$ & $19,82 \pm 1,20$ & 0,0003 \\
\hline$C 20: 3 n-3$ & $0,16 \pm 0,05$ & $0,14 \pm 0,06$ & $0,12 \pm 0,02$ & $0,11 \pm 0,07$ & \\
\hline$C 20: 5 n-3$ & $1,29 \pm 0,26$ & $0,99 \pm 0,23$ & $0,84 \pm 0,15$ & $0,99 \pm 0,12$ & 0,0011 \\
\hline C24:0 & $0,10 \pm 0,04$ & $0,08 \pm 0,02$ & $0,06 \pm 0,02$ & $0,05 \pm 0,01$ & $0,0071^{*}$ \\
\hline$C 22: 6 n-3$ & $7,14 \pm 0,92$ & $8,36 \pm 1,08$ & $7,41 \pm 0,99$ & $8,30 \pm 0,98$ & 0,0375 \\
\hline
\end{tabular}

( $p$ value $<0,05$ for those fatty acids with significant differences among groups in ANOVA or * Kruskal - Wallis test).

higher concentration of C22:6 n-3 and total n-3 PUFA in liver phosphatidylcholine of rats fed CLA-enriched diet. Moreover, they detected in this group the increased gene expression of $\Delta 6$-desaturase and increased conversion of C18:3n-3, but they linked that with the low concentration of C18:2 n-6 in that diet. However, in our study the LA was the predominant fatty acid in B1 and D1 group (Figure 1). That supports the hypothesis about the dependence between CLA supplementation and ALA metabolism. Senkal et al. observed that administration of long chain n-3 PUFA enriched diets lead to increased incorporation of EPA and DHA both in serum and tissues (liver, gut mucosa and tumour). They claim that diet can modify not only lipid profile of different tissues but also their immune response, especially inflammatory response [25]. The data presented by Eder et al. show that increased CLA intake and decreased n- 6 fatty acids administration can lower the concentration of several eicosanoids, which indicates that CLA can also modulate the immune response [24]. However Banni at al., who used in their experiment CLAenriched butter, observed the differences in the concentration of C18:1, C18:2, C18:3 between the two dietary groups, in both neutral lipids and phospholipids. Only C20:4 content in some of the phospholipid fractions was significantly lower in group with high CLA intake [26]. That disagrees with our results.
Moreover, not only diet but also carcinogenic agent treatment had great influence on fatty acids profile, both in serum and in microsomes of the investigated groups. The lover levels of C17:1, C18:0, C18:2 n-6, C20:4 n-6 were observed in serum and microsomes of DMBA-treated groups, whereas C18:2 n-6 and C18:3 n-3 showed the opposite tendency. Hoffmann et al. also observed differences between fatty acids profile of healthy and cancerous tissues, especially the $n-3$ and n- 6 fatty acids content $[27,28]$.

Two main CLA isomers were detected in all samples of serum and microsomes obtained from CLA supplemented groups and only in few samples from A1 group. The CLA isomers were separated into two peaks, of which the first one was identified as the cis-9, trans- 11 CLA and the second one as the trans-10, cis-12 CLA. Bio-C.L.A. used as the main source of CLA for B1 and D1 group consisted of several fatty acids, with prevailing share of two CLA isomers: cis-9, trans-11CLA: $33 \%$ and cis-9, trans-11 CLA: $31 \%$. However RA was shown to be the prominent CLA isomer in each study group. Its mean content in serum was $0.37 \pm 0.11 \%$ of total fatty acids whereas trans-10, cis-12 CLA constituted only $0.13 \pm 0.07 \%$ of them. There were no significant differences in RA content in serum of B1 and D1 groups and its concentration in A1 was significantly lower than in CLA supplemented groups (Table 2). Zlatanos et al. in 


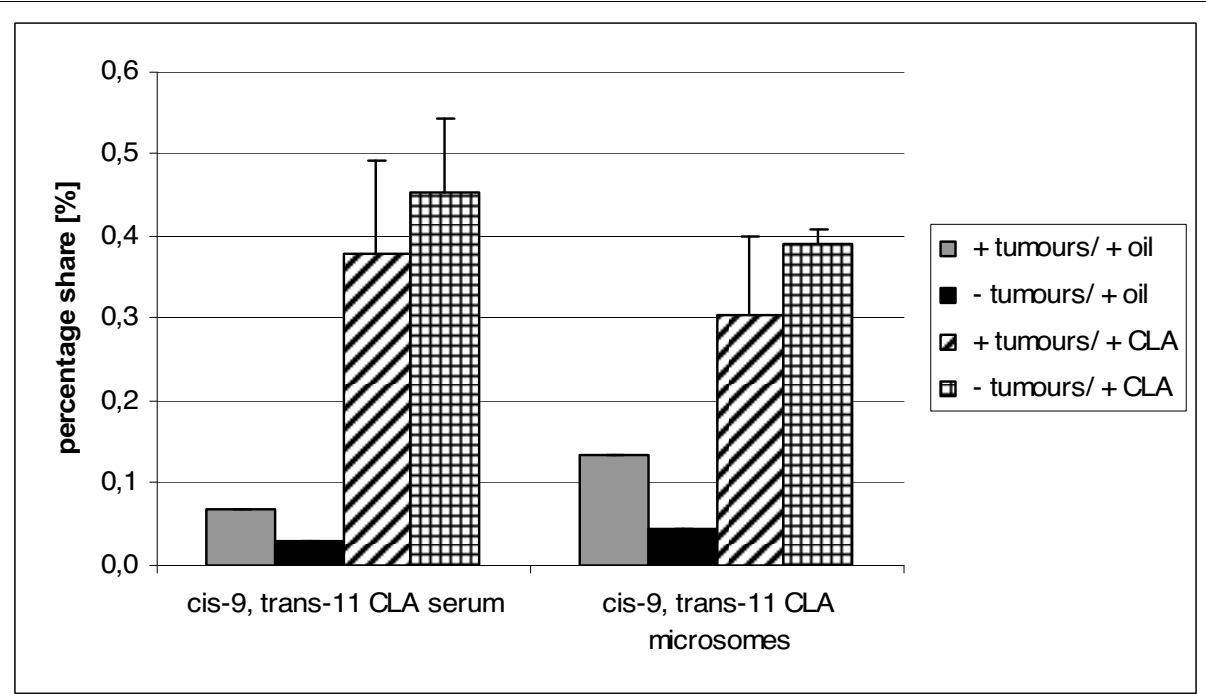

Figure 2 Content of cis-9, trans-11 CLA in serum and microsomes of individuals with or without tumours.

their experiment gave volunteers similar CLA supplement with two major isomers: cis-9, trans-11 and trans-10, cis-12 CLA (1:1), and also detected only RA in the amount of $0.20 \pm 0.02 \%$ whereas the other isomer was below the detection limit [29]. Burdge et al. got similar results for the plasma phosphatidylcholine, where cis-9, trans-11 CLA was the predominant isomer, even when the trans10 , cis-12 CLA was the main ingredient of the administrated dietary supplement [30]. The mean content of RA in hepatic microsomes was $0.27 \pm 0.11 \%$ of total fatty acids, and the concentration of the second identified CLA isomer was $0.12 \pm 0.07 \%$. We observed similar lack of differences in RA amount in microsomes between B1 and D1, and the significant lower content of this fatty acid in A1 (Table 3) as in serum samples.
We compared the CLA isomers concentration in serum and microsomes within $\mathrm{A} 1$ and $\mathrm{B} 1$ groups between tumour-bearing and non-tumour-bearing animals (Figure 2 and Figure 3). There were no significant differences either in cis-9, trans-11 CLA nor trans-10, cis-12 CLA content among the groups although the CLA amount seemed to be slightly higher in serum of B1 rats without tumours in comparison with B1 tumour-bearing animals $(0.45 \pm 0.09 \%$ versus $0.38 \pm 0.12 \%$ for cis -9 , trans- $11 \mathrm{CLA}$, and $0.18 \pm 0.07 \%$ versus $0.14 \pm 0.08 \%$ for trans-10, cis-12 CLA). Comparison of CLA isomers distribution in hepatic microsomes of $\mathrm{B} 1$ revealed the great similarity to their distribution in serum $(0.39 \pm 0.02 \%$ versus $0.31 \pm 0.10 \%$ for cis- 9 , trans- 11 CLA, and $0.20 \pm$ $0.04 \%$ versus $0.14 \pm 0.07 \%$ for trans- 10 , cis- 12 CLA). This

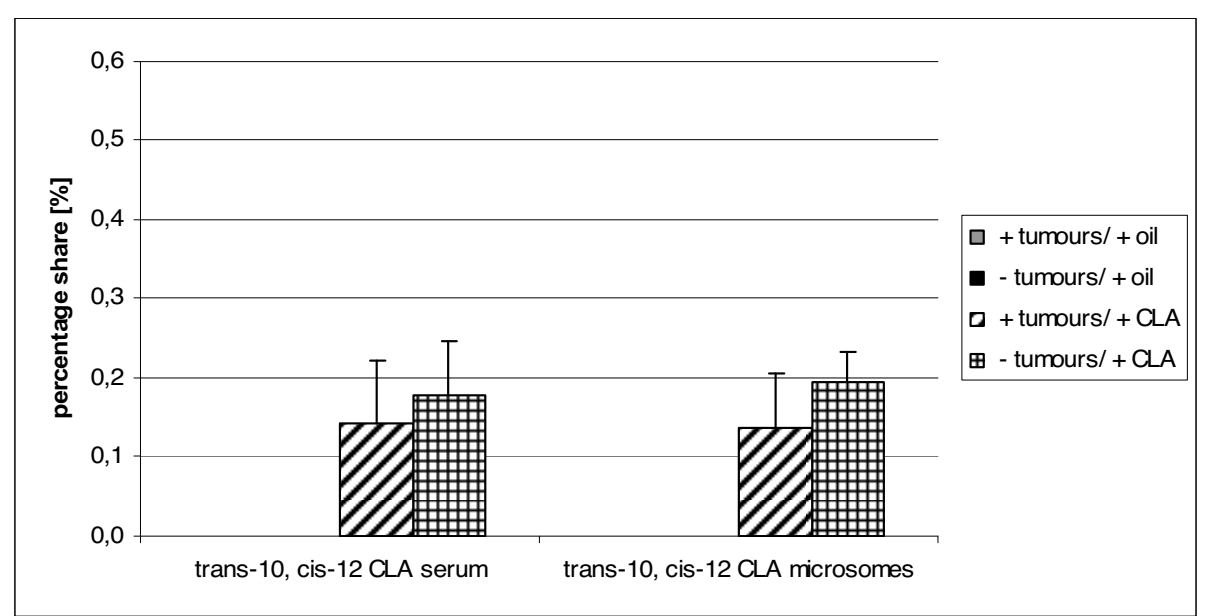

Figure 3 Content of trans-10, cis-12 CLA in serum and microsomes of individuals with or without tumours. 


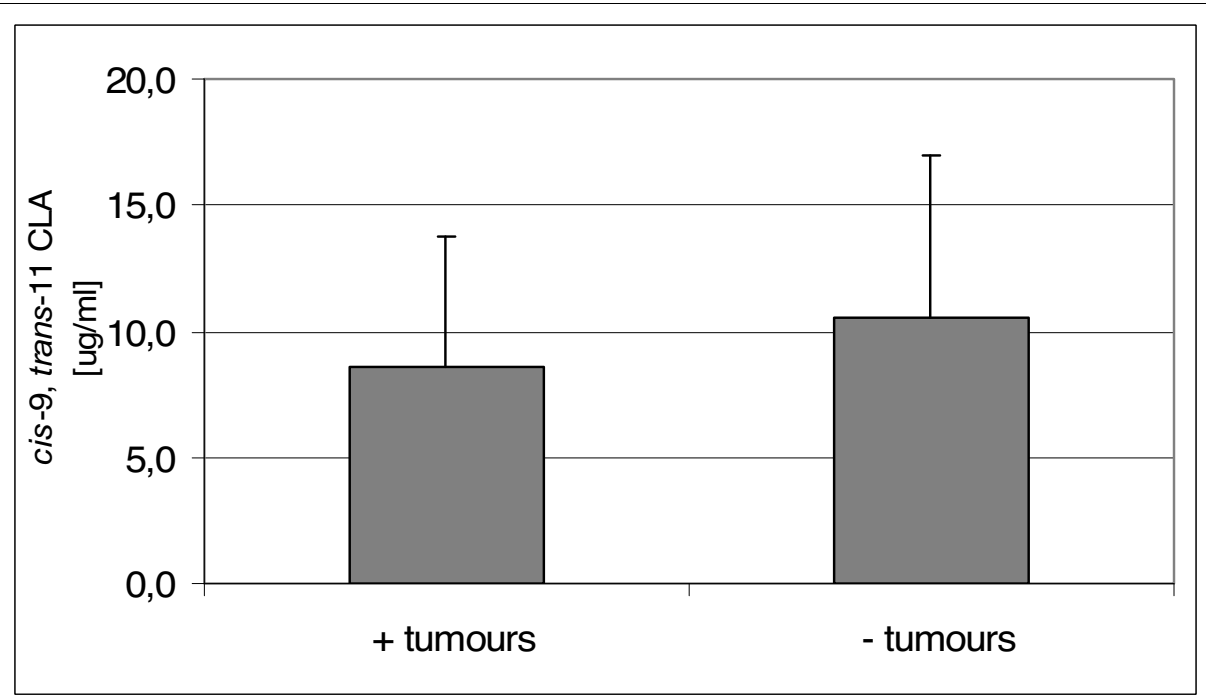

Figure 4 Content of cis-9, trans-11 CLA in serum of B1 individuals with or without tumours.

observation is in disagreement with the results of Hoffmann et al., who found CLA content to be significantly higher in total cancerous testicular tissue than in normal. Only in mitochondrial fraction of cancerous tissue CLA concentration tended to be lower than in normal tissue, whereas other subcellular fractions showed the opposite tendency [28].

Concentration of dominant RA in serum of rats fed CLA diets were $9.25 \pm 5.28 \mu \mathrm{g} / \mathrm{cm} 3$ (B1) and $6.27 \pm$ $4.05 \mu \mathrm{g} / \mathrm{cm} 3$ (D1) respectively and they did not differ significantly. Figure 4 shows the comparison of absolute RA content in B1 serum between individuals with or without developed tumours. The cis-9, trans-11 CLA content in samples obtained from individuals without noticeable tumours tended to be higher than in tumour-bearing
$(10.51 \pm 6.48 \mu \mathrm{g} / \mathrm{cm} 3$ versus $8.63 \pm 5.13 \mu \mathrm{g} / \mathrm{cm} 3)$, although no significant differences were detected. The total concentration of RA in hepatic microsomes suspension was calculated to the protein content. Its content in CLA supplemented groups was similar (B1: $0.34 \pm 0.18$ $\mu \mathrm{g} / \mathrm{mg}$, and D1: $0.26 \pm 0.29 \mu \mathrm{g} / \mathrm{mg}$ ) and the distribution pattern of this isomer in B1, depending on tumour development, was very similar to its distribution in serum (Figure 5). We observed a slight increase in RA content in non-tumour-bearing individuals $(0.47 \pm 0.41 \mu \mathrm{g} / \mathrm{mg}$ versus $0.28 \pm 0.14 \mu \mathrm{g} / \mathrm{mg})$.

\section{Conclusions}

Our findings confirm the great significance of Conjugated Linoleic Acid content in the diet on mammary

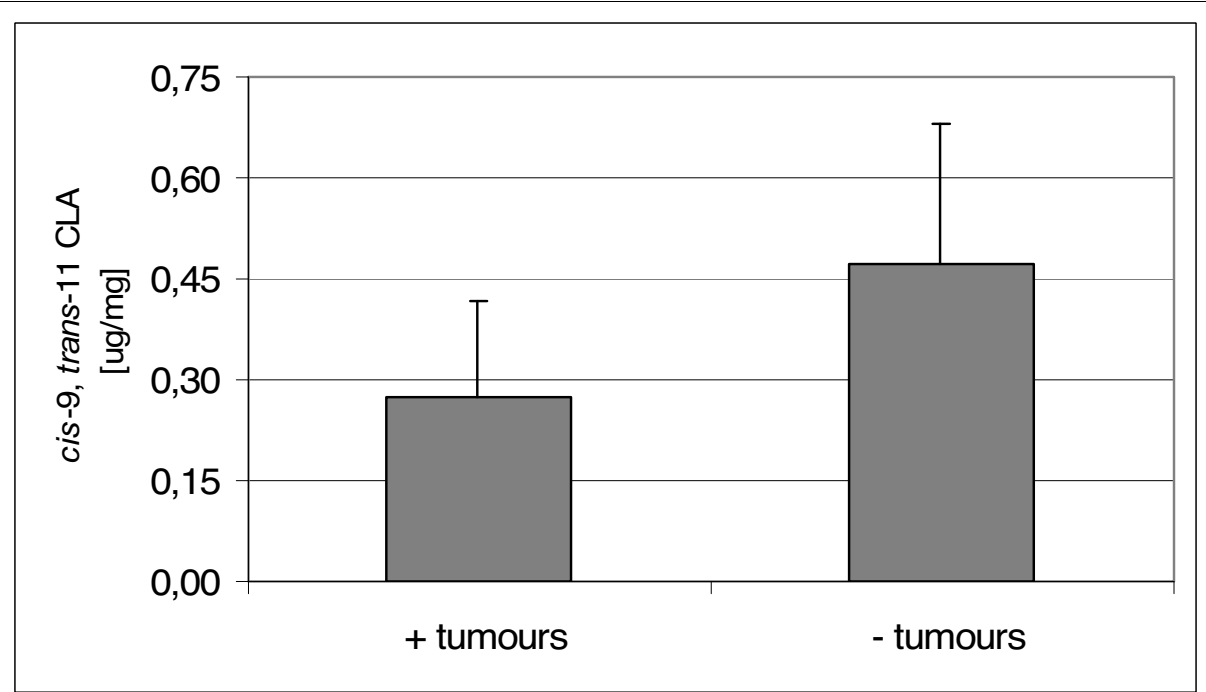

Figure 5 Content of cis-9, trans-11 CLA in microsomes of B1 individuals with or without tumours. 
carcinogenesis. CLA can inhibit the mammary tumours development and also influence the other fatty acids profile in tissues. Its content seemed to be slightly higher in serum and microsomes of rats without tumours in comparison with tumour-bearing animals. They also show that both type and amount of fatty acids in diet and environmental factors, such as carcinogenic agents, influence the fatty acids profile. On the other hand changes in fatty acids profile caused by CLA supplementation can explain the numerous activities of these fatty acids.

\section{Abbreviations}

CLA: Conjugated linoleic acid; RA: Rumenic acid; FAME: Fatty acid methyl ester; DMBA: 7,12-dimethylbenz[a]anthracene; GC: gas chromatography; DHA: Docosahexaenoic acid; EPA: Eicosapentaenoic acid; AA: Arachidonic acid; LA: Linoleic acid; ALA: $\alpha$-linolenic acid

\section{Acknowledgements}

This work was supported by the Ministry of Science and Higher Education of Poland grant N N405 362137. The authors are grateful to Pharma Nord Denmark for providing the Bio-C.L.A for the study.

\section{Author details}

'Department of Bromatology, Medical University of Warsaw, Banacha 1, 02-097 Warsaw, Poland. ${ }^{2}$ Department of Pathology and Veterinary Diagnostics, Division of Pathomorphology of Animals, Warsaw University of Life Science, Nowoursynowska 159c, 01-776 Warsaw, Poland.

\section{Authors' contributions}

$A B$ conceived, designed and carried out the experiment and performed the statistical analysis. AT coordinated the study. AD and WK carried out the GC analysis. WB carried out the histopathological examination. All authors read and approved the final manuscript.

\section{Competing interests}

The authors declare that they have no competing interests.

Received: 1 October 2010 Accepted: 2 November 2010

Published: 2 November 2010

\section{References}

1. Tanaka K: Occurrence of conjugated linoleic acid in ruminant products and its physiological functions. Animal Science Journal 2005, 76:291-303.

2. Jensen RG: The Composition of Bovine Milk Lipids: January 1995 to December 2000. J Dairy Sci 2002, 85:295-350.

3. Ledoux M, Chardigny JM, Darbois M, Soustre Y, Sebedio JL, Laloux L: Fatty acid composition of French butters, with special emphasis on conjugated linoleic acid (CLA) isomers. J Food Comp Anal 2005, 18:409-425.

4. Zlatanos S, Laskaridis K, Feist C, Sagredos A: CLA content and fatty acid composition of Greek feta and hard cheeses. Food Chem 2002, 78:471-477.

5. Sieber R, Collomb M, Aeschlimann A, Jelen P, Eyer H: Impact of microbial cultures on conjugated linoleic acid in dairy products - a review. Int Dairy J 2004, 14:1-15.

6. Lavillonniere F, Martin JC, Bougnoux P, Sebedio JL: Analysis of Conjugated Linoleic Acid and Content in French Cheeses. JAOCS 1998, 75(3):343-352.

7. Ip C, Dong Y, Ip MM, Banni S, Carta G, Angioni E, Murru E, Spada S, Melis MP, Saebo A: Conjugated linoleic acid isomers and mammary cancer prevention. Nutr Cancer 2002, 43(1):52-58.

8. Cheng JL, Futakuchi M, Ogawa K, Iwata T, Kasai M, Tokudome S, Hirose M, Shirai T: Dose response study of conjugated fatty acid derived from safflower oil on mammary and colon carcinogenesis pretreated with 7,12-dimethylbenz[a]anthracene (DMBA) and 1,2 dimethylhydrazine (DMH) in female Sprague-Dawley rats. Cancer Lett 2003, 196:161-168.

9. Kelley NS, Hubbard NE, Erickson KL: Conjugated linoleic acid isomers and cancer. J Nutr 2007, 137:2599-2607.

10. Wang LS, Huang YW, Liu S, Yan P, Lin YC: Conjugated linoleic acid induces apoptosis through estrogen receptor alpha in human breast tissue. BMC Cancer 2008, 8:208.

11. Mitchell PL, Langille MA, Currie DL, McLeod RS: Effect of conjugated linoleic acid isomers on lipoproteins and atherosclerosis in the Syrian Golden hamster. Biochim Biophys Acta 2005, 1734:269-276.

12. Lock AL, Horne CAM, Bauman DE, Salter AM: Butter Naturally Enriched in Conjugated Linoleic Acid and Vaccenic Acid Alters Tissue Fatty Acids and Improves the Plasma Lipoprotein Profile in Cholesterol-Fed Hamsters. J Nutr 2005, 135:1934-1939.

13. Valeille K, Férézou J, Amsler G: A cis-9,trans-11-conjugated Linoleic acidrich oil reduces the outcome of atherogenic process in hyperlipidemic hamster. Am J Physiol Heart Circ Physiol 2005, 289:H652-H659.

14. Valeille $K$, Férézou J, Parquet M: The Natural Concentration of the Conjugated Linoleic Acid, cis-9,trans-11, in Milk Fat Has Antiatherogenic Effects in Hyperlipidemic Hamster. J Nutr 2006, 136:1305-1310.

15. Blankson H, Stakkestad JA, Fagertum H, Thom E, Wadstein J, Gudmundsen O: Conjugated linoleic acid (CLA) reduces body fat mass in overweight and obese humans. J Nutr 2000, 130:2943-2948.

16. Gaullier JM, Halse J, Hoye K, Kristiansen K, Fagertun H, Vik H, Gudmundsen O: Supplementation with Conjugated Linoleic Acid for 24 Months is Well Tolerated by and Reduces Body Fat Mass in Healthy, Overweight Humans. J Nutr 2005, 135:778-784.

17. Gaullier JM, Halse J, Hoye K, Kristiansen K, Fagertun H, Vik H, Gudmundsen O: Conjugated linoleic acid (CLA) supplementation for one year reduces body fat mass in healthy, overweight humans. Am J Clin Nutr 2004, 79:1118-1125.

18. Nagao K, Inoue N, Wang YM, Hirata J, Shimada Y, Nagao T, Matsui T, Yanagita T: The 10trans, 12cis isomer of conjugated linoleic acid suppresses the development of hypertension in Otsuka Long-Evans Tokushima fatty rats. Biochem Biophys Res Commun 2003, 306:134-138.

19. Kłyszejo-Stefanowicz L: Ćwiczenia z biochemii Warsaw, Wydawnictwo naukowe PWN; 2003

20. Bondia-Pons I, Molto-Puigmarti C, Castellote Al, Lopez-Sabater MC Determination of conjugated linoleic acid in human plasma by fast gas chromatography. J Chromatogr A 2007, 1157:422-429.

21. Folch J, Lees M, Stanley GHS: A simple method for isolation and purification of total lipids from animal tissues. J Biol Chem 1957, 226:497-505.

22. Lowry OH, Rosebrough NJ, Farr AL, Randall RJ: Protein measurement with the Folin-Phenol reagents. J Biol Chem 1951, 193:265-275.

23. Jelinska M, Tokarz A, Oledzka R, Czorniuk-Sliwa A: Effects of dietary linseed, evening primrose or fish oils on fatty Acid and prostaglandin $E_{2}$ contents in the rat livers and 7,12-dimethylbenz[a]anthracene-induced tumours. Biochim Biophys Acta 2003, 1637:193-199.

24. Eder K, Slomma N, Becker K, Brandsch C: Effects of linseed oil supplementation on concentration of $(n-3)$ polyunsaturated fatty acids in liver phospholipids of rats fed diets containing either an oil rich in conjugated linoleic acids, sunflower oil or high-oleic sunflower oil. $J$ Anim Physiol An N 2005, 89:45-54.

25. Senkal M, Haaker R, Linseisen J, Wolfram G, Homann HH, Stehle P: Preoperative oral supplementation with long-chain Omega-3 fatty acids beneficially alters phospholipid fatty acid patterns in liver, gut mucosa, and tumor tissue. JPEN J Parent Ent Nutr 2005, 29:236-240.

26. Banni S, Carta G, Angioni E, Murru E, Scanu P, Melis MP, Bauman DE, Fisher SM, Ip C: Distribution of conjugated linoleic acid and metabolites in different lipid fractions in the rat liver. I Lipid Res 2001, 42:1056-1061.

27. Hoffman K, Blaudszun J, Brunken C, Tauber R, Hopker WW, Steinhart H: New application of a subcellular fractionation method to kidney and testis for the determination of conjugated linoleic acid in selected cell organelles of healthy and cancerous human tissues. Anal Bioanal Chem 2005, 381:1138-1144.

28. Hoffman K, Blaudszun J, Brunken C, Tauber R, Hopker WW, Steinhart H: Distribution of conjugated linoleic acid in total and subcellular fractions from normal and cancerous parts of human testes. Mol Nutr Food Res 2005, 49:756-762. 
29. Zlatanos SN, Laskaridis K, Sagredos A: Conjugated Linoleic acid content of human plasma. Lipids Health Dis 2008, 7:34.

30. Burdge GC, Lupoli B, Russell JJ, Tricon S, Kew S, Banerjee T, Shingfield KJ, Beever DE, Grimble RF, Williams CM, Yaqoob P, Calder PC: Incorporation of cis-9,trans-11 or trans-10,cis-12 conjugated linoleic acid into plasma and cellular lipids in healthy men. J Lipid Res 2004, 45:736-741.

doi:10.1186/1476-511X-9-126

Cite this article as: Białek et al:: Influence of diet enriched with conjugated linoleic acids on their distribution in tissues of rats with DMBA induced tumors. Lipids in Health and Disease 2010 9:126.

Submit your next manuscript to BioMed Central and take full advantage of:

- Convenient online submission

- Thorough peer review

- No space constraints or color figure charges

- Immediate publication on acceptance

- Inclusion in PubMed, CAS, Scopus and Google Scholar

- Research which is freely available for redistribution

Submit your manuscript at www.biomedcentral.com/submit
C Biomed Central 